\title{
La Politica y el Islam en el Mundo Arabe tras la Guerra del Golfo
}

Juan Montabes Pereira

La profunda crisis política que en estos días se está viviendo en Argelia que ha llevado a provocar una situación de excepción y a la suspensión de las primeras elecciones generales democráticas convocadas en ese país desde su independencia, nos ha vuelto a poner de manifiesto la inmensa capacidad de movilización de que disponen las organizaciones y movimientos frecuente y extensamente llamados fundamentalistas (1).

El aparente e intenso resurgimiento de los movimientos islamistas a lo largo y lo ancho del mundo árabe, es generalmente considerado por comentaristas y analistas internacionales occidentales como una vuelta a los orígenes, como una vuelta al Islam.

Con ello se quiere significar, de común, el retroceso ideológico y político que en buena parte de los paises árabes se ha iniciado con la extensión de este tipo de movimientos de manera generalizada, con mayor o menor intensidad según los casos particulares. Tras el fracaso en esos países de las más variadas experiencias políticas y de sus fundamentos ideológicos en los últimos cuarenta y cinco años, el islamismo se presenta en esos contextos como la verdadera y auténtica respuesta de los países árabes ante su actual situación política y social. 
El liberalismo, el socialismo e incluso los mismos nacionalismos, han sucumbido en su aplicación práctica en unas sociedarles donde sus fundamentos culturales y sociales difieren en extremo de los sistemas sociales sobre los que generalmente se reflexionó en el nacimiento de tales ideologias. Las experiencias políticas del Irán del Sha, del Egipto de Sadat o de la Argelia popular, socialista e independiente de los años sesenta y setenta, así nos lo pondrían de manifiesto.

El fracaso de la exportación-adopción indiscriminada de experiencias y doctrinas políticas occidentales hacia estas sociedades entre 1920 y finales de los años cincuenta, han podido en efecto empujar, a determinados movimientos y organizaciones, a adoptar posiciones más enraizadas, desde el punto de vista de la práctica y teoría política en sus respectivas sociedades. Desde tales postulados se pretende estrechar a gobernantes y gobernados aproximando en la teoría y en la práctica la política y la religión. Para ello nada mejor que el Islam para combinar en un solo espacio religión y política.

El respeto a las escrituras —el Corán-y a la tradición - a la sagrada tradición islámica一, según la interpretación auténtica que de ellas vienen haciendo los ulemas, se convierte en esta perspectiva como la única razón política de sentido válido. Indudablemente el añadido carismático de determinados líderes fraguará la contextura necesaria para poner en práctica tales modelos. Sin embargo, por completar el esquema weberiano, nada o poco queda a lo que la legitimidad legal-racional podría aportar a la acción política, guía y conductor primario de la vida política oceidental.

En la teoría política del Islam los principios de legitimidad que se barajan difieren sensiblemente de los que desde Occidente se han venido entendiendo como válidos en los últimos doscientos años. En opinión de Ernest Gellner en el Islam, desde sus comienzos, "coexistieron (no siempre pacíficamente) tres principios importantes de legitimidad: el principio de las escrituras, el del sagrado liderazgo y el del consenso de la comunidad, con peso especial asignado a sus miembros ilustrados". La combinación de estos tres componentes legitimadores del poder político ha frenado, como el propio sociólogo americano reconoce, conflictos continuos desde las primeras generaciones de musulmanes, cumpliendo efectivamente un papel integrador importante para esas sociedades.

La alternancia en la jerarquía de esos principios habría permitido sobreponerse a situaciones bien distintas de la historia moderna y contemporánea del mundo árabe. Es decir que en atención a la "prioridad o énfasis que se daba a cada unos de estos principios" se daba la respuesta adecuada a cada situación, acu- 
diendo a la revelación de la palabra divina, a la divina selección del mensajero y al disputado acuerdo de la iluminada comunidad o por lo menos el acuerdo de sus dirigentes cultos y letrados (2).

De los tres componentes de legitimidad, que según Gellner, pone en práctica el Islam para el ejercicio del poder se deduce un común denominador trazado por la base religiosa del ejercicio del poder. Incluso el proceso de racionalización que pudo suponer la constitucionalización de esos regímenes incluyó siempre el carácter confesional del Estado al proclamar en sus respectivos textos fundamentales el Islam como la religión adoptada por el Estado correspondiente (3).

Las causas de los fracasos detectados en el proceso de implantación de modelos experimentados en los países occidentales encontrarían bases distintas en función del país y del sistema adoptado. De todas formas unos elementos comunes podrían ser adelantados en estos momentos de manera general.

En primer lugar, y ante todo, es necesario poner de manifiesto que en el camino a la independencia de la mayor parte de los países árabes se desarrollaron unos procesos de cambio, por lo general promocionados o controlados por la potencias coloniales, que se limitaron a las esferas administrativas y técnicas. Por contra los cambios en las esferas sociales y culturales quedaron relegados a un segundo término o, más a menudo, ni siquiera existieron. De esta manera en los procesos de descolonización o independencia de los paísés árabes, los cambios introducidos en estas sociedades fueron dirigidos por lo general hacia las instituciones centrales del Estado y de la sociedad, relegando a un segundo término la periferia, mucho más amplia y en muchas ocasiones de mayor peso social.

En el terreno político, como ha escrito Eisenstadt, los cambios se centrarían en "la introducción de sistemas unitarios de administración, la unificación o regularización impositiva, el establecimiento de procedimientos judiciales modernos .y, en etapas posteriores, la introducción de tipos limitados de representación". Este conjunto de cambios no llegaría a trásladarse al orden local, con lo que más tarde o más temprano se originaría una contradicción básica: "por un lado se hicieron tentativas de establecer estructuras admininistrativas, políticas y económicas amplias y modernas, mientras que por otro estos cambios estuvieron limitados y basados en grupos locales y tribales relativamente inmutables, y en actitudes y adhesiones tradicionales" (4).

De no menos relevancia en el fracaso de los modelos de organización social y política occidental sería el proceso de formación de élites políticas en esas sociedades. Por lo general tales élites se han encontrado vinculadas, por su forma- 
ción e intereses, al pensamiento, prácticas y valores propios de las sociedades occidentales, pero al mismo tiempo condicionadas por las prácticas, costumbres, ideas y valores, de sus sociedades nativas, y, en consecuencia, ligadas a la selección que su religión propicia, es decir al Islam.

En el primer caso se respondía a una política explícita de la potencia colonial que pretende impartir nuevos tipos de educación moderna pero limitada a las élites locales selectas. Entre ellas habría que resaltar la importancia que las élites militares han tenido para estos países no sólo en sus respectivos procesos de descolonización sino también, incluso, de los tímidos intentos de modernización que a este respecto han existido en algunas sociedades árabes.

En el segundo plano permanecerían las pautas de autoridad tradicional de origen tribal y religioso que, sobre todo en las periferias, se mantendrían prácticamente inalteradas con el paso de los años.

Estas contradicciones contenidas en lo que podríamos denominar como políticas cosméticas de cambio para el desarrollo y modernización sociales, encontrarían en el terreno político sus máximas expresiones. Como explica acertadamente Eisenstadt, tanto las potencias coloniales como los gobernantes nativos estaban interesados en mantener la fidelidad política de la población en aras de una mayor estabilidad del nuevo sistema. Para ello "tendían a mantener un tipo de obediencia e identificación relativamente pasivo, y estaban listos para utilizar, donde fuera posible las fidelidades tradicionales existentes, o para transferirlas a la nueva estructura, sin mayor modificación en sus orientaciones sociales y culturales básicas (5).

Vinculado a ello habría igualmente que resaltar el desconocimiento. generalizado de las bases o de las pautas de la cultura política de esos países, no sólo por los gobiernos occidentales sino incluso también por la propias élites nativas. La ausencia de estudios especializados de carácter sociopolítico que pusiesen de manifiesto las claves sociales correspondientes, así como la mediación histórica de la religión, han sido dos de las constantes en los procesos de creación de los nuevos Estados árabes y de lo que es más grave aún, de la práctica política seguida en sus primeras fases. Este alejamiento de la realidad social, obviamente bien distinta de la realidad occidental, ha provocado, por lo general, una falta de adecuación entre estructura y cultura políticas. Este desfase o gap cultural habría provocado que sólo por vía de la imposición, la dominación o cuando no la represión generalizada, se hayan podido mantener inalterados durante años regímenes políticos de más que dudosa consideración democrática. 
En esta enumeración de causas comunes del fracaso de las ideologías políticas occidentales en el mundo árabe habría también que incluir aquéllas que con una base económica, han podido condicionar las pautas generales de esos sistemas. El alto grado de dependencia económica de esos países, con una estructura económica tan variada y distinta como.la que puede darse entre Kuwait y Mauritania, bien sea en cuanto a materias primas bien sea en cuanto a mercados, ha imposibilitado un desarrollo integral de esas sociedades $y$, en consecuencia, el fracaso de las teorías del desarrollo que tanta incidencia pudieron tener en un primer momento no sólo para estos países, sino también y con otro resultado, para otros procesos de transición a la democracia como en los de los países de la ribera norte del Mediterráneo.

En este contexto procesos políticos tales como los que está viviendo en estos días Argelia podrían ser reveladores de la insuficiencia de estos sistemas para dar respuesta a las exigencias sociales que aunque no generalmente expresadas sí manifiestamente presentes, en mayor o en menor medida en estas sociedades árabes. En el caso argelino más allá del dato meramente cuantitativo del amplio número de apoyos electorales o de personas movilizadas por el Frente de Salvación Islámico (FIS) (6), desde Occidente han llamado profundamente la atención no sólo las formas con las que se presentan sino también los contenidos sobre los que se sustentan tales actuaciones. Desde la óptica de la cultura política occidental propia del racionalismo ilustrado, difícilmente se llega a entender cómo esa ingente masa de fieles-militantes pueden lanzarse a la calle al grito de " $N$ i carta constitucional ni Constitución, sólo la palabra de Dios y de Mahoma" (7).

Sè podría pensar que tal slogan no es más que la reacción más o menos visceral de unos cientos de miles de personas enloquecidas por una fiebre religiosa que pretenden traspasar las barreras de lo terreno, para alcanzar en este valle los privilegios del paraíso. Como de forma gráfica ha expresado Bichara Khader con respecto a la situación descrita "la vuelta al Islam les parece a muchos —árabes- un salvavidas. Frente al vacío ideológico el Islam se convierte en un refugio de seguridad. Frente al autoritarismo de los regímenes, él aparece, al contrario, como la expresión de una participación popular. Frente a las escandalosas desigualdades, da la impresión de borrar las diferencias y nivelar las clases" (8).

En cualquier caso el fenómeno debe ser considerado como algo mucho más profundo e intenso que va más allá de manifestaciones particulares y esporádicas. En primer lugar porque desde hace más de un siglo el mundo árabe ha visto resurgir y posteriormente languidecerse corrientes islámicas, fundamentalis- 
tas, o integristas de todo tipo. No es casual en este sentido que, como afirma Khader, "cada vez que el movimiento nacional árabe entra en una fase de repliegue o de reflujo, los neo islamistas reaparecían en la delantera de la escena para canalizar los descontentos y dar nuevas esperanzas a unas masas deprimidas" (9). En segundo lugar hay que tener en cuenta que tras el llamado fundamentalismo islámico subyace toda una elàboración teórico-ideológica-religiosa que circunda en torno al fenómeno descrito. El fundamentalismo sunní, representado por la doctrina de los Hermanos Musulmanes, en su tendencia más pacífica que intenta la consecución del poder por la vía política, toma como estandarte de su actuación el siguiente enunciado: No hay más Constitución que el Corán (10).

Efectivamente estas declaraciones podrían sorprender la razón politica del bon pensant occidental al chocar frontalmente con la base de la racionalidad de la política del penśamiento ilustrado. Los fundamentos contractualistas del actual modelo de Estado difícilmente pueden encajar y mucho menos comprenderse, sino es a través de explicaciones simplistas y desatinadas del fenómeno y de la sustancia de tales manifestaciones que nos reenvían a la teoría política del Islam.

Es necesario adelantar de forma explícita y sin paliativos que desde las premisas del Islam determinados conceptos tremendamente interiorizados y asumidos como naturales por las culturas políticas occidentales, en la cultura musulmana no tienen una correspondencia directa o lo que es más importante quizás ni tan siquiera existen. Es por ello que para comprender el Islam en sus componentes políticos debemos de tener constancia, entre otras, de la inexistencia de la idea de Estado, tal y como desde el siglo XVI lo entendemos desde los llamados Estados-nación.

Esta noción-concepto eưropeo de Estado es sustituida por la idea de Comunidad de los Creyentes (Umma) que unidos por el contrato de sumisión (Islam) es efectuado entre los propios individuos y Dios. Tan sólo se puede admitir que la Comuñidad se pueda subdividir en entidades políticas menores a consecuencia de factores y exigencias de orden geográfico, de comunicaciones o incluso de historias nacionales particulares (Corán, 49:13).

En cualquier caso, como ha puesto de manifiesto Zartman, "esta entidad política no tiene ni personalidad moral ni estatuto jurídico y ni el Corán ni el pensamiento jurídico-religioso le conceden tal función" (11). De ahí derivaríamos igualmente que las ideas, conceptos e instituciones ligadas al desarrollo del Estado liberal en el mundo occidental carecen no ya sólo de sentido, sino incluso de correlato en la teoría política del Islam. Instituciones como la representación política, 
conceptos como el de soberanía o Estado de Derecho carecen de sentido dentro del pensamiento y práctica política islámica, por más que, como señalábamos al principio, se haya pretendido exportar o implantar tales ideas de forma automática e indiscriminada.

Habría que señalar, en contrapartida, el gran desconocimiento que desde Occidente se ha tenido sobre la organización y modelos políticos del Islam, de tradición y práctica tan enraizados y desarrollados como los modelos occidentales. Tengamos presente que desde el siglo VII en que el Profeta Mahoma predica su religión monoteísta en la Península Arábiga, los contenidos políticos comienzan a estar presentes a través de una institución: la umma islámica. En el año 622 Mahoma establecería los tipos y modelos de organización de la Comunidad Islámica a través de lo que vino a llamarse como Constitución de Medina (12). Esta Comunidad organizada políticamente a través de tal constitución, y mal llamada de común por arabistas como Estado, se expandería, como ha señalado María Jesús Vigueras Molins, "rápidamente desde la India hasta el Atlántico", conformando-sus características y estructuras políticas. Estos planteamientos quedarían marcados, desde esos primeros momentos "por esta amplitud espacial propia de la civilización islámica, cuyo ámbito cronológico es en la actualidad muy extenso, pues ha cumplido en la actualidad catorce siglos" (13).

De todas formas, y antes de avanzar en el desarrollo del tema deberíamos hacer una precisión fundamental sobre lo que concierne al Islam y al Mundo o Nación árabe que nos permita discernir con claridad conceptos que, utilizados de común como sinónimos, reflejan realidades y representan ideas o nociones diferenciadas en sus contenidos y referentes.

Con respecto a la expresión mundo árabe se produce comúnmente una polisemia que debemos aclarar. Con esta expresión no hacemos exactamente referencia ni a una nación, ni a una raza, ni a una religión. Este término no puede definirse más que a través de una serie de componentes.

El árabe es en primer lugar UNA LENGUA, que a diferencia de las demás no sólo es un vehículo de comunicación y una estructura de pensamiento como muchas otras lenguas. Se trata de una lengua sagrada, desde su propia consideración, en la cual Dios ha expresado su mensaje a los hombres por la intermediación del Profeta. Su escritura misteriosa, su sintaxis dificil, sus expresiones a la vez precisas y múltiples cierran el acceso a los extranjeros, es decir a los no musulmanes.

El árabe califica también a un TERRITORIO. En él vive una comunidad de árabes o de hombres que se dicen tales. Sobre el mismo pesan siglos de histo- 
ria de asentamientos no árabes que han marcado su propio desarrollo como nación o comunidad y del que la actualidad es buena expresión de tales tipos de conflictos.

Se puede también hablar de una NACION árabe, aun cuando sus componentes no sean en sentido estricto arabófonos. Como dice la plegaria, lo esencial es querer sentirse árabe, incluso aunque lingüísticamente se pertenezca a otro grupo. Sin embargo la imposibilidad histórica de construir una verdadera nación política resalta también las dificultades y diferencias que se integran en el seno de esa comunidad.

Todo ello ha podido llevar a algunos autores a poner en duda, cuando no a negar la existencia de tal entidad. Es así como Felix Ortega llega a afirmar que "realmente, el nacionalismo árabe no ha existido nunca. La palabra ha sido usada por amigos y enemigos. Pero es sólo eso, una palabra, un estereotipo que esconde la complejidad de una sociedad en la que lo único que une es el idioma y, eventualmente, la fe"(14).

En definitiva LENGUA, TERRITORIO, NACION y VOLUNTAD DE ARABISMO entran en la definición que daba el manifiesto del Comité Nacionalista de Siria en abril de 1936:

La nación árabe es la población que habita sobre el territorio árabe y que está unida por la comunidad de lengua, de mentalidad de recuerdos históricos, de hábitos y de costumbres, de intereses y de esperanzas. Nuestra patria, la patria árabe está formada por la regiones comprendidas en los límites siguientes: al Norte el monte Taurus y el Mediterráneo, al Sur el Océano árabe (Indico), las montañas de Abysinia, las cordilleras del Sudán y del. Sahara; al Oeste con el Océano Atlántico y sobre las costas de Syria el Mediterráneo; al Este las Montañas del Irán y el golfo de Basora (Pérsico) (15).

El mundo árabe se define también por su religión. Es necesario, no obstante, no confundir arabismo e Islam. Estos son dos conceptos que no se solapan, aunque muy a menudo ellos vienen a reafirmarse mutuamente. El Islam es la religión de la casi totalidad de los árabes. Hay de todas formas árabes no musulmanes (los árabes cristianos de Medio Oriente), como gráficamente se expresa en el Cuadro Final. Pero junto a ello y en contrapartida la mayor parte de los musulmanes no son árabes.

Por tanto podríamos concluir de todo ello que es un árabe el que Allah ha elegido como mensajero; es la lengua árabe la que transmite o vehicula el mensaje religioso, es a partir de la Arabia como se ha organizado la expansión árabe y la que le da nombre a la misma etnia. 
Descritos hasta aquí los caracteres definitorios de lo árabe podríamos preguntarnos si los componentes reseñados constituyen por sí misimos un factor de cohesión suficiente para definir por sí mismo a los países árabes desde Marruecos hasta Irak. Junto a ellos, en efecto podríamos enunciar toda una serie de factores diferenciadores (temperamentos opuestos, dialectos, sectas, niveles de riqueza, condiciones naturales y geográficas) que pondrían seriamente en cuestión un tratamiento unitario para ese conjunto. Pese a ello el arabismo se suele presentar también en los textos constitucionales y en la literatura política como una profesión, como una manifestación. Jacques Berque llama a este afán por superar estas diferencias como la "energía unitaria" del pueblo árabe que le lleva a las continuas tentativas de unidad.

Esta tentativas no han sido exclusivas del mundo árabe sino que también el Islamismo ha intentado trazar su propia unidad. El Panislamismo surgiría en este sentido como "un nacionalismo religioso para superar la crisis de liderazgo ejercida por el califato otomano, donde se revitaliza el concepto de umma o nación islámica y que aspira a la unidad de las tierras y los hombres del Islam". Por su parte, como ha escrito López García, el Panarabismo, que sucederá al Islamismo en el principio del siglo XX, "supone una reacción de los árabes, situados en la periferia del imperio otomano, contra su centro, tras unas décadas de decadencia en el resurgir de la idea de nación árabe en los años cincuenta de este siglo bajo el liderazgo del Egipto de Nasser" (16).

Definido de esta forma, el mundo árabe no llega a coincidir con la geografía musulmana. El mundo árabe comprendería una serie de países que se extenderían desde el Atlántico y que podríamos dejar enmarcados en tres grandes bloques:

- El Machrek (Levante) u Oriente Arabe, que incluye los países del Levante: Líbano, Jordania e Israel y Palestina; el Creciente Fértil: Siria e Irak; y los de la Península Arábiga: Arabia Saudí, Kuwait, Bahrein, Emiratos Arabes Unidos, Omán y Yemen.

- El Magreb (Poniente) u Occidente Arabe, constituido por los países del Mediterráneo (Marruecos, Argelia, Túnez y Libia) más Mauritania que pese a incluirse en la llamada Africa subsahariana ha venido formando un conjunto histórico en este bloque.

- El Valle del Nilo constituido por Égipto y Sudán.

Con independencia del papel y del lugar en que situemos el concepto de la umma islámica, sí podemos afirmar la recíproca repercusión de los aconteci- 
mientos que afectan al mundo árabe. En efecto, a pesar de las diferencias de todo orden que encontramos dentro del llamado mundo árabe la solidaridad interna que en este grupo se puede detectar ante determinadas situaciones puede en algún caso ser mayor que la que desde Occidente podríamos detectar en algunos Estados.

Por tanto pese a los puntos que anteriormente se han señalado como favorecedores de la cohesión árabe se podrían apuntar otra serie de factores favorecedores del desacuerdo o del conflicto interno. Entre ellos y en un primer plano resaltan las condiciones económicas en las que se sitúan los países antes enunciados.

De forma similar a como lo hacíamos deșde la perspectiva geográfica, desde el punto de vista económico se podrían conformar tres grandes bloques de países, de acuerdo con la clasificación que a este respecto realiza Bichara Khader en un completo y minucioso estudio socioeconómico sobre el mundo árabe (17):

a. Aquel bloque de países que podríamos considerar como ricos, o con posibilidad de equiparación económica con los países occidentales. Estos serían aquellos países con más de 5.000 $\$$ de Renta Per Cápita. Es decir que aquí deberíamos incluir a Arabia Saudí (5.433\$), Bahrein (6.513 \$), Emiratos Arabes Unidos (16.882 \$), Kuwait (11.584\$), Libia (5.439\$), Omán (5.657\$) y Qatar (15.288 \$). Esto significa que 24,3 millones de habitantes $-11,03 \%$ de la población árabe-, aporta el $42,61 \%$ del PIB del mundo árabe.

b. Un segundo bloque constituido por lo países económicamente intermedios cuyas rentas se situarian entre los 1.200 y $2.500 \$$ por persona y año. Argelia (2.273 \$), Irak (1.950\$), Siria (1.800\$), Túnez (1.315\$) y Jordania (1.134\$). En este caso estos países reuniendo el $30,85 \%$ de la población concentrarían el $36,84 \%$ del PIB.

c. Por último un tercer bloque de los que sin ningún reparo podríamos denominar como países pobres con una Renta Per Cápita inferior a los $1.000 \$$ se encontrarian: Egipto (675 \$), Marruecos (815 \$), Mauritania (420 \$), Sudán (335\$) y Yemen $(500 \$)(18)$.

Las diferencias económicas que nos revelan los datos anteriormente expuestos nos pueden dar una idea de las posibles divergencias que entre los intereses de la umma podríamos encontrar. Sólo un ejemplo que por sus trascendentales consecuencias puede ser más que revelador a este respecto. El incremento del precio del petróleo derivado de la pasada Guerra del Golfo ha situado en posiciones bien distintas a los diferentes países árabẹs en función de su condición de que fuesen productores-exportadores de petróleo o consumidores-importadores. Lo que para Argelia o Libia, por señalar sólo dos casos, ha supuesto una revalorización de 
su principal materia prima y una extraordinaria entrada de divisas, para Marruecos, Túnez o Jordania ha conllevado un fuerte endeudamiento que incrementa sus críticas situaciones económicas.

Por otro lado, la debilidad del comercio intrárabe hace que la mayoría de los países dependan en cuanto a sus exportaciones o importaciones de sus relaciones con el resto de las potencias Occidentales. Pensemos que en el caso concreto de los países del Magreb sólo un 5\% del total de sus intercambios se realiza internamente entre los cinco países que constituyen la UMA (Unión del Magreb Arabe). Paralelamente más de un $50 \%$ del total de su comercio lo realizan estos países (Marruecos, Argelia, Túnez, Libia y Mauritania) con países miembros de la $\operatorname{CEE}(19)$.

De lo que se desprende del Cuadro Final, en similares términos podríamos pronunciarnos sobre el conjunto de los países árabes, ya que sólo en el caso del Emirato de Bahrein y de Jordania aparecen otros países o conjunto de países árabés como principales clientes o proveedores comerciales.

Esa debilidad comercial del conjunto árabe hace que difícilmente se puedan trazar lazos económicos que proyecten hacia el exterior un conjunto homogéneo con fuerza suficiente para adoptar posiciones autónomas en el orden internacional.

En este contexto la llamada Guerra del Golfo ha venido a fomentar las fisuras interárabes provocando un realineamiento de los distintos países no sólo con el resto de países occidentales, sino también dentro de la geografía árabe.

Esta guerra que, a pesar del sugerente trabajo de Jean Baudrillard, sí ha tenído lugar (20), ha contribuido, junto a otros factores de orden internacional tales como el derrumbamiento de los regímenes comunistas del Este de Europa, el debilitamiento de la URSS y el auge los nacionalismos periféricos, a colocar al mundo árabe en una situación sensiblemente diferenciada de la que en los últimos treinta años, al menos, ha venido manteniendo. Esta nueva posición la podríamos sintetizar en los siguientes seis puntos:

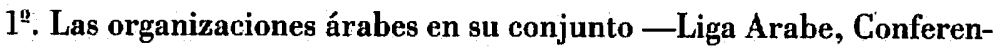
cia de Países del Golfo e incluso la Unión del Magreb Arabe- han salido tremendamente debilitadas de la resolución del conflicto. Las diversas posiciones adoptadas por los distintos países miembros en el conflicto, así como los intereses que de ellas se han derivado han incidido sobremanera en sus relaciones internas. Sólo el paso del tiempo volverá a acercar posiciones tan alejadas hoy en día como la de Egipto o Arabia y Libia o Irak, por mencionar sólo algunas de las más emblemáticas. 
$2^{2}$. Movimientos $u$ organizaciones de liberación nacional como la OLP se han visto seriamente dañadas en sus apoyos internacionales en la medida en que su causa es vista desde sus aliados árabes con la única misma posibilidad de solución, pero sin que ésta deba ser necesariamente articulada por la organización de Arafat.

$3^{\text {a }}$. La posición y apoyo que Arabia ha venido manteniendo a determinados movimientos islámicos pueden verse reducidos, cuando no eliminados, por el papel que éstos han jugado durante la Guerra. La utilización de estos movimientos por parte del régimen de Sadam Hussein que habría provocado una auténtica solidaridad popular árabe a favor de él, ha desprestigiado al mismo tiempo la política que hasta esas fechas había mantenido Arabia.

$4^{\mathbf{a}}$. El giro dado por Siria durante el conflicto a su posición tradicional con respecto a los Estados Unidos ha mostrado a éstos la posibilidad de encontrar nuevos aliados en el mundo árabe.

5⿳. La posición mantenida por Israel durante la Guerra ha puesto de manifiesto, sobre todo a determinados paises árabes, la posibilidad de arreglo pacífico que pudiera existir en torno a los territorios ocupados, siempre que se mantengan las actuales correlaciones interárabes y de éstos con los Estados Unidos.

$6^{\circ}$. Por último, con la Guerra del Golfo y sobre todo con su resolución, se habría fortalecido la posición de los Estados Unidos, y en menor medida de la CEE, como principal socio político y económico de estos países. Ello constituye a los Estados Unidos, y a Occidente en general, como el principal responsable de la estabilidad política de la zona. Una vez que el comunismo prácticamente se ha hundido y que la URSS tiene un menor protagonismo internacional es a los Estados Unidos de Norteamérica a los que les corresponderá la responsabilidad de sentar las bases de una convivencia pacífica en la zọna donde siguen existiendo intereses encontrados. La unanimidad árabe existente sobre la cuestión de Israel y los territorios ocupados obligará a los americanos a buscar una solución adecuada a las pretensiones de los ahora aliados árabes con la defensa de los intereses de su tradicional socio israelita. Como escribía recientemente Michel Faure en L'Express con respecto a este punto, "si después de la Guerra, no se llega a obtener un arreglo del problema palestino, Occidente quedará desacreditado" (21).

En definitiva todas estas consecuencias nos demostrarían la fragilidad de los intereses árabes, pese a su tremenda importancia, ante un proceso de escala internacional como el que recientemente se ha vivido en esa zona.

Un tercer y último motivo de diferenciación interárabe, en esta relación no exhaustiva, ha venido a producirse por los diferentes tipos de procesos his- 
tóricos que se han vivido en los últimos cien años en lo que hoy podríamos llamar los distintos Estados árabes. A pesar de los caracteres comunes antes enunciados con respecto a los cambios sociales y políticos generados con los procesos de independencia o descolonización de manera general, cada uno de ellos en atención a su propia estructura y a sus relaciones con la potencia colonizadora tuvo sus propias especificidades. Tales procesos han contribuido a formar unas culturas $y$, sobre todo, unas élites y un entramado de intereses que en mayor o en menor medida habrían podido condicionar las posiciones respectivas.

El hecho de que ningún país árabe haya desarrollado un sistema democrático estable en los últimos cien años nos puede poner de manifiesto hasta qué punto han podido fracasar de común las políticas seguidas en el proceso de independización y consolidación autónoma. No obstante la incertidumbre se asienta en la actualidad en las posibilidades de triunfo de los procesos de transición a la democracia que tímidamente se han iniciado recientemente. Los casos de Argelia, Túnez o Egipto no parecen más que una respuesta, también según el modelo occidental, a las profundas crisis que se vienen viviendo en esos países en los últimos años.

Entre los elementos comunes más resaltados en los procesos de transición en el Magreb, destaca en el apartado del común denominador, la existencia más o menos desarrollada y articulada de movimientos religiosos de carácter islamista con incidencia directa en el proceso político y no obstante con caracteres institucionales diferenciados .en Argelia, Túnez o Marruecos. La incompatibilidad manifiesta de los presupuestos idelógicos y religiosos de estos movimientos con los principios de las democracias pluralistas, han llevado a muchos observadores políticos a manifestar la imposibilidad de éxito de un proceso de democratización en las sociedades musulmanas. No obstante, la complejidad y desconocimiento extendido del problema, no deben llevarnos a aseveraciones rotundas que impidan un ánálisis pormenorizado y multifactorial que conjugue la posibilidad de compatibilizar la democracia con la religión musulmana (22).

Junto a él, otros factores como el neo-patrimonialismo, en expresión de Camau, o la tendencia a la juridificación de la vida social y política y judicialización del espacio neo-patrimonialista, suponen unos de los elementos comunes de mayor relevancia en cuanto a lo que a la modernización de esas sociedades afecta y que modifican sustancialmente situaciones precedentes más arriba descritas (23).

En definitiva, toda esta serie de factores específicos nos llevan a concluir la imposibilidad de aplicár o trasladar los modelos preexistentes de democra- 
tización a estas sociedades, aunque ello no signifique ignorar esos precedentes para tenerlos en cuenta en aspectos tales como el papel de los liderazgos del antiguo y del nuevo régimen, la articulación política de la oposición y del propio régimen, la estructura de clases y económica de las sociedades o el mencionado de los militares para comprender plena y más ricamente los procesos que en estos países se están viviendo.

La incertidumbre de estos procesos nos hace coincidir con Camau cuando a modo de conclusión del trabajo antes mencionado proclama sus dudas sobre la indefectibilidad de los procesos de transición que se están viviendo en el Magreb. Los problemas sociales existentes, las dificultades políticas expuestas, la extrema situación económica de esos países, así como las actuales coordenadas del orden internacional, hacen surgir las dudas sobre las posibilidades de éxito de estos procesos. Más aun cuando nos encontramos ante una ausencia teórica que establezca las pautas de tales procesos de democratización y que, en todo caso, en atención a los factores expuestos parecen "jugar un papel de reforzamiento de la tutela estática del autoritarismo" (24) actual más que de incentivo a la democracia.

En conclusión y ante la situación expuesta, se pone de manifiesto la necesidad de profundizar en el estudio de los procesos políticos del mundo árabe. Es así como a través de las aportaciones de politólogos, economistas, historiadores o sociólogos se posibilitará no sólo conocer en profundidad las claves de tales procesos, sino además se cumplirá con la responsabilidad que la comunidad científica tiene a este respecto en cuanto a la aportación de los conocimientos y análisis necesarios que permitan una mejor canalización de tales transiciones hacia unos regímenes democráticamente más abiertos y con mayores grados de libertad y de justicia social. 


\section{ALGUITAS GARACTERISTICAS SOCIOZCONOMICAS DE LOS PATSES ARABES}

\begin{tabular}{|c|c|c|c|c|c|c|c|c|c|c|}
\hline \multirow{2}{*}{$\begin{array}{l}\text { Aknsin } \\
\text { Pol.. 14,43 (I) }\end{array}$} & \multicolumn{2}{|c|}{ Religiones } & \multicolumn{2}{|c|}{ Etnios } & \multirow{2}{*}{$\frac{\text { Deudu }}{15.3(2)}$} & \multirow{2}{*}{$\begin{array}{c}\text { P.1.B. } \\
100\end{array}$} & \multirow{2}{*}{$\begin{array}{c}\begin{array}{c}\text { Renta } \\
\text { per Capita }\end{array} \\
\mathbf{5 . 4 3 3 \&}\end{array}$} & \multirow{2}{*}{$\frac{\text { Proveedlores }}{\text { USA, JPN }}$} & \multirow{2}{*}{$\begin{array}{l}\begin{array}{l}\text { Cllentes } \\
\text { polf́tico }\end{array} \\
\text { JPN. INV (j) }\end{array}$} & \multirow{2}{*}{$\begin{array}{l}\text { Réginien } \\
\begin{array}{l}\text { Monaryuia } \\
\text { alı. Istam. }\end{array}\end{array}$} \\
\hline & $\begin{array}{l}\text { Sunies } \\
\text { Shíps: }\end{array}$ & $\begin{array}{r}47 \% \\
2 \%\end{array}$ & Arulues & $99 \%$ & & & & & & \\
\hline $\begin{array}{l}\text { Ancei.u } \\
\text { Pob. 24, } 60\end{array}$ & $\begin{array}{l}\text { Suníes } \\
\text { Barébor }\end{array}$ & $\begin{array}{l}\text { 94\% } \\
22 \%\end{array}$ & Arulues & $76 \%$ & 18,2 & 50,5 & $2.273 \$$ & (ABF, PVI) & CKR, USA & $\begin{array}{l}\text { Repúbl. } \\
\text { Presideta:- }\end{array}$ \\
\hline $\begin{array}{l}\text { BAliRFiK } \\
\text { Pob. } 0,49\end{array}$ & $\begin{array}{l}\text { Sunies : } \\
\text { Shiíes }\end{array}$ & $\begin{array}{l}60 \% \\
40 \%\end{array}$ & Aralues & $y y \%$ & - & 5,1 & $0.513 \$$ & ArS. CKE & USA, JPN & $\begin{array}{c}\text { Monaruquia } \\
\text { abs. }\end{array}$ \\
\hline $\begin{array}{l}\text { EcivTi } \\
\text { Pob. 53,08 }\end{array}$ & $\begin{array}{l}\text { Sunies } \\
\text { Cristianos }\end{array}$ & $\begin{array}{r}94 \% \\
6 \%\end{array}$ & $\begin{array}{l}\text { Arabes } \\
\text { Nubfas }\end{array}$ & $\begin{array}{r}9 y \% \\
1 \%\end{array}$ & 28,3 & $54, y$ & $640 \$$ & CEt, USA & C.E., USA & Presillencinl. \\
\hline $\begin{array}{l}\text { Enthxtos A, } \\
\text { Pob. 1,55 }\end{array}$ & $\begin{array}{l}\text { Suníes } \\
\text { Shifes: }\end{array}$ & $\begin{array}{l}87 \% \\
13 \%\end{array}$ & Aralses & $99 \%$ & - & 27,6 & $16.882 \$$ & CEL, JYD & JIPN, PVD & $\begin{array}{l}\text { Monarcquía } \\
\text { abs. Islam. }\end{array}$ \\
\hline $\begin{array}{l}\text { IRAK } \\
\text { Pob. 18,28 }\end{array}$ & $\begin{array}{l}\text { Shites } \\
\text { Suniog }\end{array}$ & $\begin{array}{l}51 \% \\
46 \%\end{array}$ & $\begin{array}{l}\text { Aralies } \\
\text { Kurilos }\end{array}$ & $\begin{array}{l}72 \% \\
22 \%\end{array}$ & $50-8.5$ & 45.1 & $1.950 \$$ & C.EF, USA & CEE, USA & $\begin{array}{l}\text { Rigimen } \\
\text { Militar. }\end{array}$ \\
\hline $\begin{array}{l}\text { Inan } \\
\text { Pob, 54,90 }\end{array}$ & $\begin{array}{l}\text { Shtuíes } \\
\text { Sunitea }\end{array}$ & $\begin{array}{c}96 \% \\
3 \%\end{array}$ & $\begin{array}{l}\text { Persay } \\
\text { Araber }\end{array}$ & $\begin{array}{r}15 \% \\
2 \%\end{array}$ & 5,0 & - & $3.264 \$$ & $\begin{array}{c}\text { CHE, JPN } \\
.\end{array}$ & CBB, JPN & $\begin{array}{l}\text { Repábliea } \\
\text { Islámica. }\end{array}$ \\
\hline $\begin{array}{l}\text { JOHIDANIA } \\
\text { Pob. } 4,10\end{array}$ & $\begin{array}{l}\text { Sunins } \\
\text { Crist./Otros }\end{array}$ & $\begin{array}{r}92 \% \\
8 \%\end{array}$ & $\begin{array}{l}\text { Aralies } \\
\text { Otros }\end{array}$ & $\begin{array}{r}95 \% \\
5 \%\end{array}$ & 5,53 & 4,1 & $1.134 \$$ & CIX, Or Meal & CEE, Or Mesl & $\begin{array}{c}\text { Monarquía } \\
\text { absoluta. }\end{array}$ \\
\hline $\begin{array}{l}\text { KLWAit } \\
\text { Pob, 2,05 }\end{array}$ & $\begin{array}{l}\text { Sunies } \\
\text { Stuíes. }\end{array}$ & $\begin{array}{l}79 \% \\
21 \%\end{array}$ & Arabes & $100 \%$ & 7,2 & 20,9 & $11.584 \$$ & CEK.JPN & PVD; CBE: & $\begin{array}{l}\text { Monarifuia } \\
\text { abs. Islám. }\end{array}$ \\
\hline $\begin{array}{l}\text { LuHa } \\
\text { Poh. 4,39 }\end{array}$ & Sunires & $918 \%$ & $\begin{array}{l}\text { Arabess } \\
\text { Beralaer }\end{array}$ & $\begin{array}{r}92 \% \\
6 \%\end{array}$ & $\mathbf{3 , 3}$ & 33,6 & $5.420 \$$ & CWK.JPN & CEF, ULSS & $\begin{array}{l}\text { Régimen } \\
\text { Mititar. }\end{array}$ \\
\hline $\begin{array}{l}\text { ManRLicos } \\
\text { Pob: 24,5 }\end{array}$ & Sunít:s & $98 \%$ & $\begin{array}{l}\text { Arulues } \\
\text { Benólıer }\end{array}$ & $\begin{array}{l}66 \% \\
33 \%\end{array}$ & 20.8 & 11,2 & $950 \$$ & CKE. USA & CEE, CARM & $\begin{array}{l}\text { Monarıuía } \\
\text { alısoluta. }\end{array}$ \\
\hline $\begin{array}{l}\text { Maunimania } \\
\text { Pob. 1,97 }\end{array}$ & Suníed & $99 \%$ & $\begin{array}{l}\text { Arabies } \\
\text { Beréber }\end{array}$ & $\begin{array}{r}62 \% \\
-20 \%\end{array}$ & 2,1 & 0,7 & $\because \quad 480 \$$ & Fil & JPN, JPVD & $\begin{array}{l}\text { Réfimen } \\
\text { militar. }\end{array}$ \\
\hline $\begin{array}{l}\text { Omani } \\
\text { Pob. } 1,42\end{array}$ & $\begin{array}{l}\text { Sunies } \\
\text { Ibadit }\end{array}$ & $\begin{array}{l}40 \% \\
60 \%\end{array}$ & Arulies & $99 \%$ & 2,9 & 9,8 & $5.657 \$$ & $\mathrm{CB}, \mathrm{EXU}$ & JPN, COR & $\begin{array}{l}\text { Monarquía } \\
\text { abst: Islám. }\end{array}$ \\
\hline $\begin{array}{l}\text { Qstakt } \\
\text { Pob. 0,35 }\end{array}$ & $\begin{array}{l}\text { Sunies } \\
\text { Shifea }\end{array}$ & $\begin{array}{l}90 \% \\
10 \%\end{array}$ & Aralute & 9y\% & 0.7 & 5,4 & $15.288 \$$ & CBE, lVII & JPN. IPVD & $\begin{array}{l}\text { Monartpuía } \\
\text { alost. jslúm. }\end{array}$ \\
\hline $\begin{array}{l}\text { Tuxex } \\
\text { Pob. } 7,99\end{array}$ & Sunies & $99 \%$ & $\begin{array}{l}\text { Aralues } \\
\text { Beréber }\end{array}$ & $\begin{array}{r}97 \% \\
3 \%\end{array}$ & 5,6 & 8,9 & $1.315 \$$ & FR, IPYD & CABE, CAIBM & $\begin{array}{l}\text { Regnública } \\
\text { Presidenc. }\end{array}$ \\
\hline $\begin{array}{l}\text { Sum } \\
\text { Pób, 11,72 }\end{array}$ & $\begin{array}{l}\text { Sunfes: } \\
\text { Crist. }\end{array}$ & $\begin{array}{l}75 \% \\
10 \%\end{array}$ & $\begin{array}{l}\text { Aralses } \\
\text { Kurdus }\end{array}$ & $\begin{array}{r}89 \% \\
8 \%\end{array}$ & 5,0 & 20,7 & $1.800 \$$ & CHE, JINN & PVD, URSS & $\begin{array}{l}\text { Réginnen } \\
\text { militar. }\end{array}$ \\
\hline $\begin{array}{l}\text { YMALN } \\
\text { Pob. 10,17 }\end{array}$ & $\begin{array}{l}\text { Sunies } \\
\text { Zuidies }\end{array}$ & $\begin{array}{r}5 \% \\
35 \%\end{array}$ & Arabes & $98 \%$ & 5,4 & 4,0 & $581 \$$ & PVD, CEE & IFA, USA & En Tranisición. \\
\hline & & & & & & & & & & \\
\hline $\begin{array}{l}\text { 1. Millones de } \\
\text { 2. Miles de Mil } \\
\text { 3. PVD: Países }\end{array}$ & rosonay: & . & ' & 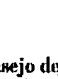 & 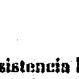 & . & . & & . & . \\
\hline
\end{tabular}

FUKNTES: Los porcentajes do otnins y raligiones provienen del Allas du Mundi Arabe, Rafic Botastani et Philippe Fargues. Ed. Bordas, París, 1990. La población, Deuda Exterior, Renta Per Cápita y Proveedores y Clientes de El Estado del Mundo 199l. Anuario Geopolítico y Mundial. Ediciones Akal. Madrid, 1991, El Producto Interior Bruto proviene do Bichara Khader: El Mundo Arabe ante el anio 2000. Eitudios de sociologia y economía. Editorial CanuArabia. Mradrid, 1988. 


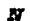

o

$\mathbf{T}$

$\boldsymbol{s}$

1. El término fundamentalismo, generalmente utilizado para referirse a los grupos islámicos radicales y militantes puede llevar a confusión en sí mismo y mucho más si no va acompañado del adjetivo islámico. En efecto como recientemente ha escrito Bernard Lewis (El lenguaje politico del Islam. Taurus. Madrid, 1990), el término fundamentalismo tiene un origen y un desirrollo contextual netamente cristiano. Fs un término "que parece haber entrado en uso a principios de este siglo y se refiere a algunás iglesias y organizaciones protestantes, en especial a acpuellas que afirman el origen divino y la infalibilidad de la Biblia". Este se contrarrestaría con la corriente imperante hoy en día en la práctica totalidad del cristianismo que tiende a una visión de las Escrituras más crítica e histórica. Es en este sentido en el que Lewis señala que todos los musulmanes en su actitud ante el Corán son fundamentalistas. Donde según este autor los fundamentalistas islámicos se separan del resto de los musulmanes es en su escolatiscismo y en su legalismo ya que no se bașan sólo en el Corán sino también en las tradiciones del Profeta y en el cuerpo de enseñanza teórica y legal transmitida a través de los ulemas o sabios en las ciencias religiosas que deciden lo que en la sociedad islámica debe ser considerado como legítimo o ilegítimo según sus interpretaciones coránicas y la vida del Profeta. Es por' todo ello preferible hablar, en puridad de términos, de Islamismo para referirnos al fenómeno descrito, que de fundamentalismo, no sólo por los orígenes del término sino también por no incluir a la totalidad de los musulmanes en esa categoría, exclusiva de determinados sectores.

2. Gellner, Ernest: Nación y nacionalismo Alianza Edit: Madrid, 1988. Pág. 150.

3. La totalidad de los textos constitucionales árabes en vigor proclaman al Islam como la religión del Estado. Cfr. López García, B. y Fernández Suzor, C.: Introducción a los regímenes y Constituciones árabes. Centro de Estudios Constitucionales. Madrid, 1985.
4. Eisenstadt, S. N.: Modernización. Movimientos de protesta y cambio social. Amorrortu Editores. Buenos Aires, 1972. Pág. 187.

5. Ibidem, pág. 189.

6. Recordemos que en las últimas elecciones municipales de Argelia el FIS llegó a obtener el $54 \%$ de los votos emitidos. En Egipto los Hermanos musulmanes obtuvieron 38 diputados en las elecciones de 1987. En Túnez los Independientes, apoyados por la Nahda obtuvieron el. 13\% de los votos en las elecciones municipales de 1989. En ese mismo año los islamistas obtuvieron en Jordania 30 de los ochenta escaños de que consta el Parlamento de ese país.

7. Ver diario El Pais de 4 de junio de 1991, sección Internacional, pág. 10.

8. Khader, Bichara: El Mundo Arabe ante el año 2000. Estudios de Sociologia y Economia. Editorial CantArabia. Madrid, 1988. Pág. 13.

9. Ibidem, pág 13 .

10. Cfr. Martín Muñoz, Gema: El fundamentalismo Islámico como actual fuerza desestabilizadora, aproximación al tema en el Magreb. En Africa Internacional El empuje del Islam. Iepala Editorial, Madrid, 1989. Págs. 39 y 40.

1 1. Zartman, William I.: "Pouvoir et Etat dans l'Islam" en Pouvoirs, $\mathrm{n}^{\mathrm{Q}}$ 12, 1983. Pág. 5.

12. Cfr. - Vernet, Juan: Mahoma. Edit. Planeta. Barcelona, 1987.

- Montgomery, W.: Mahoma, profeta y hombre de Estado. Edit. Labor. Barcelona, 1973.

- Lamdton, Ann K.S.: State and government in medieval Islam. Oxford University Press. Oxford, 1981.

13. Vigueras Molins, M" Jesús: "El mundo islámico" en Vallespín, Fernando (Ed.): Historia de la Teoría política.(Vol. I). Alianza Editorial. Madrid, 1990. Pág. 325.

14. Ortega, Félix: "¿Pero hubo alguna yez nación árabe?", en la Revista GeoEspecial, dedicada monográficamente al Islam. Geo, n" 59. Pág. 96. 
15. Citado en Flory, Korany, Mantran, Camau y Agate: Les régimes politiques arabes. PUF. París, 1990. Pág.17.

16. López García, Bernabé: "Estrategia y política del mundo árabo-islámico en el contexto internacional. Elementos para una interpretación de los sucesos del Golfo", en Ayeres. Cuadernos de Historia, Año II, $n^{\circ} 4$. Págs. 18-19.

17. Khader., Bichara: El Mundo Arabe ante el año 2000. Estudios de Sociología y Economia. Editorial CantArabia. Madrid, 1988.

18. Los datos referidos a la población, Producto Interior Bruto y Renta Per Cápita han sido obtenidos de El Estado del Mundo 1991. Anuario económico y geopolítico mundial. Ediciones Akal. Madrid, 1990. Todos ellos están referidos al año 1989.

19. Cfri. Información Comercial Española: Argelia, Marruecos, Túnez. Las economías de los países del norte de Africa. Sus relaciones con España. Publicación de la Secrètaría de estado de Comereio. $N^{2}$ 2.283. Del 10 al 16 de junio de 1991.

20. Baudrillard, Jean: La Guerra del Golfo no ha tenido lugar. Edit. Anagrama. Barcelona, 1991.

21. Faure, Michel: "Convoitises au pays de l'or noir", en $L^{\prime}$ 'Express, $\mathbf{n}^{\circ} \mathbf{2 . 0 6 5}$, de 7 de febrero de 1991. Especial "Le Monde arabe et l'Occident". Pág. 35.

22. Cfr. Revue Povoirs $n^{2} 12,1983$. Dedicado monográficamente a este tema.

23. Camau, M.: "Le Maghreb", en Flory, M. y otros: Les régimes politiques arabes. Op. cit. Pág. 434 y ss.

24. Camau, M.: "Le Maghreb", en... Op. cit. Pág. 446. 